\title{
Selecting Key Resilience Indicators for Indigenous Community Using Fuzzy Delphi Method
}

\author{
Yung-Ping Tseng ${ }^{1} \oplus$, Yu-Chin Huang ${ }^{2, *}$, Mei-Syuan $\mathrm{Li}^{1}$ and You-Zih Jiang ${ }^{3}$ \\ 1 Department of Tourism, Leisure \& Hospitality Management, National Chi Nan University, \\ Nantou 54561, Taiwan; yptseng@ncnu.edu.tw (Y.-P.T.); msli@mail.ncnu.edu.tw (M.-S.L.) \\ 2 Graduate Program of Sustainable Tourism and Recreation Management, National Taichung University of \\ Education, Taichung 403454, Taiwan \\ 3 Ph.D. Program in Strategy and Development of Emerging Industries, National Chi Nan University, \\ Nantou 54561, Taiwan; aa0928887194@gmail.com \\ * Correspondence: ychuang.ntcu@gmail.com
}

check for updates

Citation: Tseng, Y.-P.; Huang, Y.-C.; Li, M.-S.; Jiang, Y.-Z. Selecting Key Resilience Indicators for Indigenous Community Using Fuzzy Delphi Method. Sustainability 2022, 14, 2018. https://doi.org/10.3390/su14042018

Academic Editor: Víctor

Jesús García-Morales

Received: 26 December 2021

Accepted: 4 February 2022

Published: 10 February 2022

Publisher's Note: MDPI stays neutral with regard to jurisdictional claims in published maps and institutional affiliations.

Copyright: (C) 2022 by the authors. Licensee MDPI, Basel, Switzerland. This article is an open access article distributed under the terms and conditions of the Creative Commons Attribution (CC BY) license (https:// creativecommons.org/licenses/by/ $4.0 /)$.

\begin{abstract}
Resilience is the concept that emphasizes change and adaptation and focuses on the capacity to absorb shocks and still maintain function. How can an Indigenous community assess the resilience of the tribe when it is affected by an array of obstacles? What are the assessment factors of resilience? This study consolidated relevant literature on resilience through in-depth interviews and the Fuzzy Delphi Method (FDM) to identify the resilience indicators for Indigenous community development. It eventually identified 5 domains, 26 types, and 45 evaluation indicators. The final indicators are divided into five domains: economic, social, cultural, environmental, and policy. The social resilience indicators: "the ability to overcome obstacles", "the ability to accept stimuli", and "the degree of connection between tribal and external resources" were not mentioned in the past studies of resilience. For the first time, the following cultural resilience indicator was also included: "maintain the traditional ancestral teachings and respect for ancestral norms". Finally, this study suggests that follow-up research may extend these resilience indicators and apply them to other Indigenous tribes. These 26 types of assessment will also be the factors that must be considered in the process of adaptation and reconstruction when the community is faced with emergencies or catastrophes.
\end{abstract}

Keywords: resilience; Indigenous community development; indicator construction; Fuzzy Delphi Method (FDM)

\section{Introduction}

The concept of resilience stems from physics, ecology, and disaster management. In 1973, the ecologist Holling first introduced the concept of resilience into the field of ecology and defined it as "the capacity of a system to absorb, disturb and reorganize while undergoing change so as to still retain essentially the same function, structure, identity, and feedbacks". Then, some researchers put forward different views, defining resilience as: "the speed of a system to recover to its original stable state after encountering disturbances [1]". Social resilience is the ability of groups or communities to adapt to external stresses due to social, political and environmental changes [2]. Folke [3] also indicated that the understanding of social processes (e.g., social learning, mental models and knowledge-system integration, agents and actor groups, social networks, institutional and organizational inertia and change, adaptive capacity, transformability, and systems of adaptive governance) are essential for ecosystem management services. From the perspective of communities and organizations, resilience is the ability of the relevant private sector, government, and society to maintain adequate service levels after a system catastrophe $[4,5]$.

The entire globe is affected by climate change, global warming, and other diverse influences, as well as uncertainty, insecurity, and factors such as economic, environmental, 
and the COVID-19 pandemic impacts. The natural environment has encountered a reduction in resources, biodiversity, and the productivity of the ecosystem, which has led to a decline in the resilience of the ecosystem and increasing vulnerability in many parts of the world [6-8]. In the context of sustainability, the emphasis is mainly on the protection and the vulnerability of affected areas, which appears to be insufficient to address the above issues adequately. Especially regarding the issues of vulnerability in the Indigenous communities, the label "vulnerable" and the accompanying set of assumptions are often generated by outsiders who may be unfamiliar with the complexities of local culture, economy, and capabilities [9]. "Resilience" however, emphasizes change and adaptation and is very important for maintaining ideal ecosystems; thus, the maintenance and improvement of the resilience of ecosystems is the basis for the sustainability of a place [10]. Research on resilience has been the subject of many concerns in the past decades, and the relevant empirical research has been mainly viewed from a socio-ecological perspective, looking at issues in the areas of disasters, socioecology, economic and organizational behavior, etc. [3,11-14]. In recent years, researchers have turned their attention to how to develop resilience in the community [1]. Community resilience is a top priority in enhancing communities' preparedness to recover from disasters [15].

Taiwan is a unique environment in which to explore Indigenous resilience to disasters [16]. The "Alang Tongan" is located in Nanfeng Village, Nantou County, Taiwan. It is rich with abundant natural resources and features the traditional characteristics of the Seediq (one of sixteen Indigenous tribes in Taiwan). It is very suitable for development as an eco-destination. It was most famous historically for its collection of butterfly specimens in the late 19th Century [17]. Due to the previous overhunting of butterflies, an earthquake measuring 7.3 on the Richter scale in 1999, landslides, and other natural disasters, it has suffered severe damage to both the community as well as to the natural environment. These, coupled with the severe outflow of the younger generation from the community, have also affected the development and economy of the tribe. These environmental damages, the loss of the traditional culture, and other negative issues have become obstacles to the growth of the tribes.

Recently, some of the tribal youth have returned home, intending to revitalize the tribe. More than two hundred species of butterflies were recorded, and an interpretation system was also installed. Wetlands were excavated to build ecological ponds for environmental education and ecotourism.

The Alang Tongan is endowed with abundant natural resources, along with many external organizations that assist (e.g., the Community Development Association, the Indigenous Tribe Revitalization and Cultural Education Foundation, the Endemic Research and Conservation Centre, the Soil and Water Conservation Bureau, the New Homeland Foundation and the National Chi Nan University, etc.). However, how can an Indigenous tribe assess its resilience when it is affected by an array of obstacles? What are the assessment factors of resilience? Therefore, this study uses the Alang Tongan as a case study and develops resilience indicators to be used for the revitalization of the Indigenous community.

\section{Literature Review}

In the following sections, we discussed the definition of resilience, its foundation theories, and the measurement indicators.

\subsection{Definition of Resilience}

Many scholars apply resilience in different areas; for example, in psychology, they use the concept of the power of resilience in the study of an individual coping with adversity [18]; while in physics and engineering, resilience (elasticity) is one of the material properties. In addition, resilience has been extended to the ability to recover or adapt from unfortunate or changing circumstances, including the ability to create learning institutions, address changing environments, maintenance of core values, and understand the 
dynamic social and environmental systems, as well as encouraging mobility, creativity, and innovation in a community [2].

The social resilience that has often been discussed recently is due to social, political, and environmental changes that lead to the ability of groups or communities to adapt to stressful external disturbances [11]. Folke et al. [19] indicated that resilience is the capacity of a social-ecological system to continually change and adapt yet remain within critical thresholds. For the Indigenous people, the tribe is equivalent to the concept of community. Based on the Indigenous Peoples Basic Law [20], a tribe refers to a group of Indigenous persons who form a community by living together in specific areas of the Indigenous peoples' regions and follow traditional norms with the approval of the central Indigenous authority. The community is an entity with a geographical boundary and a shared fate; previously, this described the complexities of the general public, the neighborhood, and the formal institutions, industry, etc. in a large complex of geopolitical units, and consisted of the architectural, natural, social and economic environments combining in a complex manner [21].

In addition, from a community and organization point of view, resilience is the ability of the relevant private sector, government, and society to maintain services after a systematic disaster [5,22]. Different scholars have put forward their concepts, and these are compiled in Table 1:

Table 1. The summarized concept of community resilience.

\section{The Concept of Community Resilience}

Have the ability to rebound and the effective use of materials and economic resources to recover after encountering disaster

The ability of individuals and communities to deal with continuous long-term stress; the ability to find undiscovered intrinsic advantages and resources to respond effectively.

Resilience is the community's ability, skills, and knowledge to enable the community to participate fully in disaster recovery and reconstruction

Social politics, social culture, and psychological resources that can promote the safety of residents and ease adversity

The ability of community members to take meaningful and deliberate collective action to correct the impact of the problem, including the ability to interpret the environment, intervene and continue to move forward

The existence, development, and engagement of community resources by community members to thrive in an environment characterized by change, Magis (2010, p.401) [28] uncertainty, unpredictability, and surprise.

Refers to a wide variety of things, including the social, economic, political, and environmental attributes that influence the prospects for sustainability. Resident communities can use the perspective that it offers to evaluate their Tsai, Wu, Geoffrey, and Linliu (2016) [29] situations in tourism development.

Community resilience identifies the ability of a community to survive a disturbance. It is a bounce-back from various shocks associated with poor Musavengane and Kloppers (2020) [30] devolution, poor funding, and a lack of power-sharing.

When a community needs post-disaster reconstruction, to increase resilience, the community must develop economic strength and reduce potential risks and the unfair distribution of resources. In summary, community or tribal resilience is made up of those factors that enable the community and residents to efficiently create tolerance, adaptation, and responses to environmental, social, economic, cultural, or other threats and shocks. 


\subsection{Classic Theory Foundation of Resilience}

The classical theories based on the concept of resilience included the cup and ball model, tourism area life cycle (TALC), and the cycle of adaptability. They all elucidated the response speed and the response methods when the system was affected by external forces.

The cup and ball model theory is often used to describe the concept of restoring force and emphasize the differences between different types of restoring forces [5]. This model describes how the ecosystem transitions into different states. When the ecosystem is disturbed, the ball is forced to leave the bottom of the cup and move further up to a different position within the cup; eventually, the ball will return to the bottom of the cup. In the assumption of ecological resilience, there are multiple stability domains; when the shape changes or is disturbed by external disturbances, the system changes past a certain critical point, and the system will change the stability field to enter into a new ecological system status. For example, fires, droughts, and other external disturbances can cause a forest ecosystem to be transformed into a grassland ecosystem [31]. Therefore, ecological resilience is defined as the size of the stability domain, i.e., the total amount of disturbances the system could bear before entering into another critical state [5].

The tourism area life cycle proposed by Butler [32] is similar to the concept of resilience; it studied the role of residents in the tourism development of a tourist destination and further explained the rise and recession of the tourism development. This theory uses the increase in the number of visitors as an external disturbance factor for resilience. When the number of visitors reaches the peak, the stagnation stage will be achieved as well. Thus, a tourist destination with resilience will move into a reorganization stage, but on the other hand, tourism development will go into a declining trend. Butler divides tourism development into six stages: exploration, involvement, development, consolidation, stagnation, and the final stage of either rejuvenation or decline as possible alternatives.

The ecologist Holling first advocated the use of the adaptive circle theory to explain and analyze the resilience of social ecology [11,33]. It is believed that the ecosystem is circulated through four individual stages: rapid growth and exploitation, conservation stage, release stage, renewal and reorganization stage [5,34,35]. Throughout the entire adaptive cycle, there are different degrees to each stage; the concept of resilience changes is embedded throughout it.

\section{Resilience Measurement and Indicators}

Berkes [36] revealed four strategies enhancing resilience to future change: (1) learning to live with change and uncertainty, (2) fostering ecological, economic, and cultural diversity, (3) increasing the range of knowledge for learning and problem-solving, and (4) creating opportunities for self-organization. Choi and Sirakaya [37] constructed the sustainable development indicators of community tourism development-a total of 125 items. The recovery capacity-related factors included: social cohesion, community health and safety, cultural management and protection, social and cultural structures, architecture, government support, and so on. Among them, political and social indicators accounted for 60 items, about one-half, reflecting the importance of social-related indicators in sustainable development of community tourism.

Pfefferbaum et al. [27] pointed out that one of the factors of community resilience is "support and conservation", which refers to community concerns about the needs and wellbeing of members. Magis [28] researched the community resilience of socially sustainable developments and claimed eight community resilience dimensions: community resources, resource development, resource engagement, impact, equity, strategic action, collective action, and active agents. Besides, Norris et al. [21] proposed that community resilience emerges from four primary adaptive capacities: economic development, social capital, communication information, and community competence. In recent years, Lew et al. [7] explored similarities and differences in community sustainable development and resilience, and these were divided into four types: local government budgeting, environmental knowledge, community well-being, and social support systems. 
However, the construction of resilience indicators needs to include the ability of the social environment to restore the original appearance and facets after the interference of natural disasters. Chiang \& Chang [38] built sustainable community indicators and divided them into five main categories: environmental and ecological protection, community economic development, community life networks, community culture preservation, and a suitable governance mechanism. Cajete [39] offered the following considerations for building a sustainable Indigenous community: (1) understanding resources and premise, (2) the acknowledgment of spiritual purpose, (3) practiced relationship, (4) deep commitment, and (5) learning from the experiences of other Indigenous people.

Past research on resilience has focused on disasters, social ecology, the economy, and organizational behavior; community resilience-related issues have received more and more attention in recent years. However, how does the process of Indigenous community development adjust to rapid changes (such as natural disasters), and how does it adapt to slow changes (e.g., loss of traditional culture)? Therefore, this study will be based on the construction of the Alang Tongan resilience indicators as the reference for future Indigenous resilience research.

\section{Materials and Methods}

According to the Article 21 of The Indigenous Peoples Basic Law, when governments or private parties engage in academic research in Indigenous land, tribe, and their adjoin-land which owned by governments, they shall consult and obtain consent by Indigenous peoples or tribes, even their participation, and share benefits with Indigenous people. The Tribal Council recognizes all the research processes. Since August 2014, the research team has developed a partner relationship with the tribe. The tribe elders also organized an official tribal council meeting in March 2015, formally agreeing that the Alang Tongan would participate in the academic research with us.

This study summarizes the relevant indicators of resilience $[4,14,37,38,40-42]$ based on past studies. Preselected resilience indicators were derived from in-depth interviews with community stakeholders. The Fuzzy Delphi Method (FDM) was then applied to identifying resilience indicators. The research field, sampling procedures, indicator construction process, and FDM steps are described below.

\subsection{Research Field}

The Seediq people are characterized by their weaving culture and facial tattoos. They uphold Gaya (the ancestral rules) as their code of living and value the worshipping rituals of ancestral spirits. In the 18th to 19th Century, the Seediq people developed their territories in Nantou and Hualien on both sides of the Central Mountain Range. During Japanese colonization in the early 20th Century, as the colonial government reckoned, the Seediq territory was government property, and due to the racism of the colonial police, Mona Rudo, chief of the Mahepo Community Seediq, led the Wushe Incident that shocked the world in 1930. It was the last armed resistance against Japanese colonization in Taiwan. The incident shocked the Government-General of Taiwan and the international community and is significant in the history of Taiwan [43].

Regarding ethnic identification, there are three subgroups of Seediq, Tgdaya, Seediq Toda, and Seediq Truku requested ethnonym rectification as "Seediq Balay, Sejiq Balay, and Seediq Bale" respectively from the government in 2000. In 2008, the government thus recognized the ethnicity of the whole Indigenous group as Seediq. Most of Taiwan's Indigenous tribes are geographically located in the mountainous interior. According to the authorities, 576,792 of Taiwan's 23.4 million people are Indigenous, belonging to 16 tribes recognized by the Taiwan administration. The 16 officially recognized Indigenous tribes are considered the northernmost representatives of Austronesian culture [44].

Seediq is one of sixteen Indigenous tribes with a total population of 10,793. The Alang Tongan is located in Nantou County, Renai Township, at the confluence of the Nanshan and 
Meixi Creek (Figure 1). The two Seediq communities of the Tongan and the Sipo formed it. The size of Nanfeng Village is 79.58 KM2.

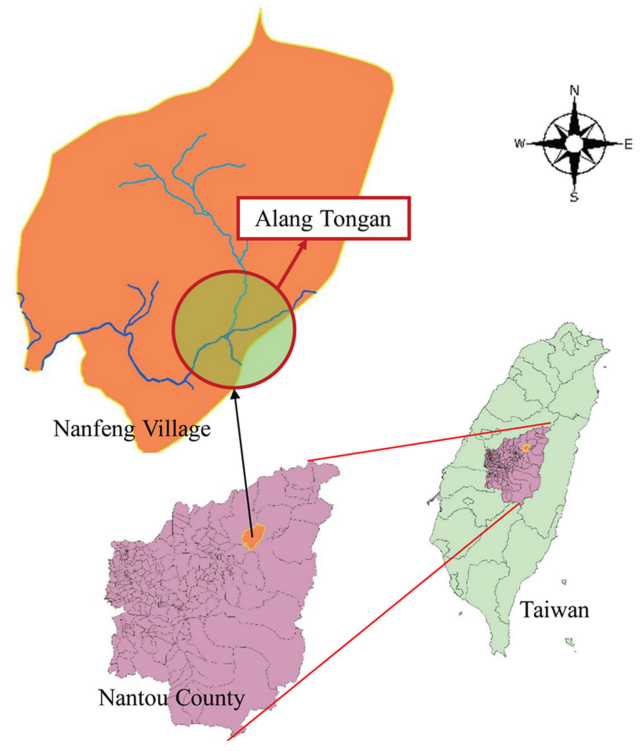

Figure 1. The Alang Tongan location map. Source: Drawn by this study.

In the past, the Alang Tongan was Taiwan's most important site for the collection of butterfly specimens. In 1994 under the "Comprehensive Community Development" movement, the tribal youth were actively involved in the reconstruction of the tribes, and the development of individual workshops also enabled weaving skills to be inherited. Unfortunately, it suffered from an earthquake and a typhoon in 1999 and 2004, respectively, causing severe damage to the ecological and social environments. Over the past few years, through local conservation, rehabilitation, and the push for regional economic development, the revenue from ecological and cultural tourism development by the Alang Tongan reached NT 18 million in 2019.

Taiwan, however, is an island symbiotic with disasters, and Indigenous tribes are often faced with unending difficulties and challenges because of natural and humanmade calamities. For example, in June 2019, the tribe was attacked by a heavy monsoon downpour; in less than two days, it received more than $700 \mathrm{~mm}$ of rainfall, resulting in soil slippages and landslides in many tribal areas. Earth and rock also covered two of the seven newly excavated ecological rehabilitation ponds initially planned as an ecological education park. Much soil erosion, flooding, and destruction of roads caused tribal traffic blockages, loss of crops, and other negative impacts (see Figure 2). This, coupled with the media's actions that reported the disaster for several days, affected the Indigenous community development and indirectly stigmatized the tribe's destination image. Taiwan is located in the subtropical region along the typhoon approach route; there will be more severe tests in the future during periods of extreme climate change. In addition, most Indigenous people in Taiwan living in geographically high-risk areas suffer vulnerabilities to the risks of climate change [45], thus they will require more adaptability to disasters and more resilient abilities. In a nutshell, understanding Indigenous resilience mechanisms can enhance disaster relief knowledge and provide more guidance to local governments and social organizations such as NGOs and practitioners [45].

\subsection{Indigenous Resilience Index Construction Process}

This study divides the construction process into three stages to establish an effective and objective resilience assessment framework of Indigenous community development. The first stage is the convergence of past research on resilience. The second stage uses the in-depth interviews derived from the Indigenous community development resilience indicators; the third stage is the further use of FDM expert questionnaires for selecting, deleting 
non-consensual items, and finally establishing the Indigenous community development resilience index.

In this study, we synthesized past research on resilience $[7,14,27,28,31,38,41,42]$. The indicators are divided into five aspects of economic, social, cultural, ecological environment, and policies.

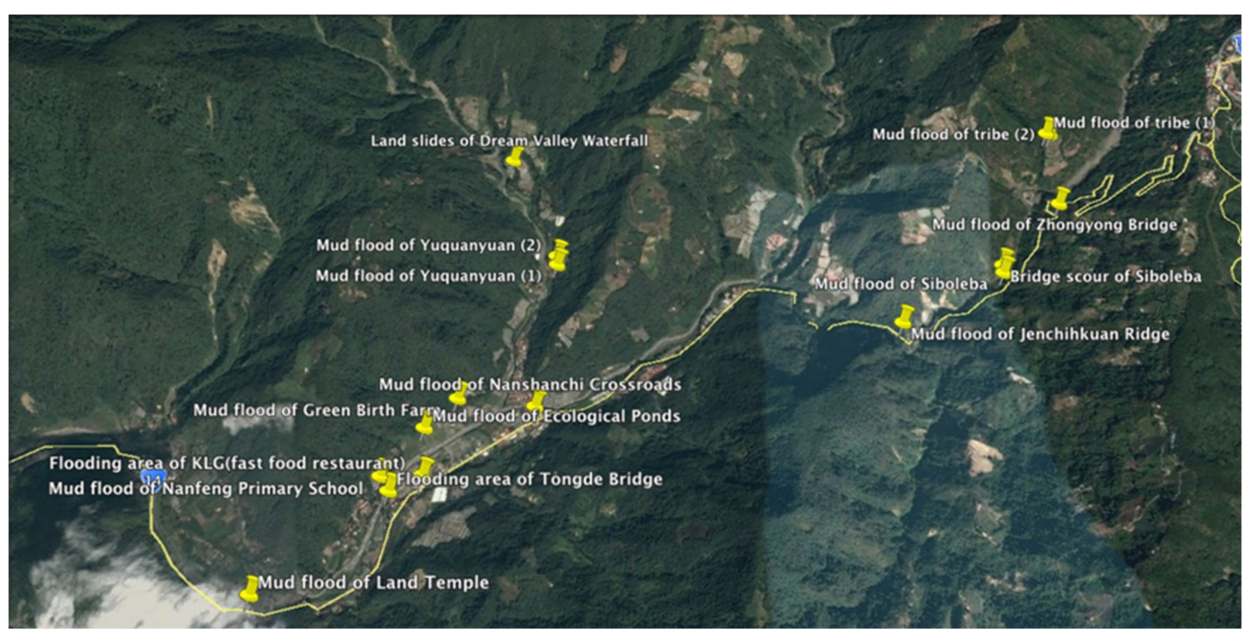

Figure 2. Disaster sites in the Alang Tongan in the monsoon season of June 2019. Source: Drawn by this study.

\subsection{Resilience Indicator Development through In-Depth Interview}

In order to understand the resilience of the Alang Tongan, purposive sampling was used. Nine interviewees were selected in the period between December 11th and 30th, 2019; each interview took about $60 \mathrm{~min}$. A semi-structured interview method was used, and questions were developed based on past research on sustainability and resilience indicators [6].

Based on literature review and in-depth interviews, this study drew out the content of the interviews and further added and constructed the indicators suitable for the tourism development and post-disaster restoration of the Alang Tongan, and divided the indicators into the five aspects of economic, social, cultural, ecological environment, and policy. Through in-depth interviews, the newly added constructed indicators are: "Ability to Remove Obstacles", "Ability to Accept Stimulus", "External Links", and "Indigenous Traits" for the community. In the domain of cultural aspect, a new indicator of "to maintain the traditional ancestral teachings and respect for ancestral norms" was added. Types of indicators derived from the past literature and in-depth interviews are shown in Table 2. The Fuzzy Delphi method was used to select or delete indicators in the next stage.

\subsection{Sampling Procedures}

In terms of the sample size of the Fuzzy Delphi survey, this study chose to work with a total of 17 people. This matches the argument from Rowe and Wright [46] that the number of experts can start from 5 to 20 people based on their areas of expertise. Seven experts from academics (who have been engaged in ecotourism, sustainable development, community development, and teaching and research related to Indigenous people); one expert in the tourism industry (who has been counseling Indigenous affairs for at least 4 years); three experts from central government (Council of Indigenous People); one from a non-profit organization (that has worked on the fostering of national art development and traditional culture for at least 10 years), and five local Indigenous people (who have lived in the community for more than 3 years and have participated in community development related matters). Expert questionnaires were distributed between 15 April 2020, and 8 May 2020; all questionnaires were returned and deemed to be valid. All interviewees were contacted by telephone first, and then 16 were filled in on-site; 1 response was sent by e-mail. 
Table 2. Types of resilience indicators derive from interviews.

\begin{tabular}{|c|c|c|c|}
\hline & Assessment Indicators & & Assessment Indicators \\
\hline \multirow[b]{2}{*}{$\begin{array}{l}\frac{2}{0} \\
\frac{0}{0} \\
\infty \\
\dot{4} \\
\dot{4}\end{array}$} & \multirow{2}{*}{$\begin{array}{l}\text { A1. Mutual support and care (Chiang \& Chang, } 2014 \text { [38]) } \\
\text { A2. Diversified community participation (Chiang \& Chang, } 2014 \text { [38]) } \\
\text { A3. Community effectiveness (Khalili et al., 2015 [42]) } \\
\text { A4. Social, community involvement (Khalili et al., } 2015 \text { [42]) } \\
\text { A5. Social support (Khalili et al., 2015 [42]) } \\
\text { A6. Social cohesion (Choi \& Sirakaya, 2006 [37]; Khalili et al., 2015 [42]) } \\
\text { A7. Educational resources \& accessibility (Ciftcioglu, 2017 [14]) } \\
\text { A8. Sense of belonging to the tribe (Khalili et al., 2015 [42]) } \\
\text { A9. Creativity and innovation ability (Khalili et al., 2015 [42]) } \\
\text { A10. Communication and information (Khalili et al., 2015 [42]) } \\
\text { A11. Mechanisms to encourage youth to return home (Lew et al., 2016 [7]) } \\
\text { A12. External links } \\
\text { A13. Indigenous traits } \\
\text { A14. The ability to remove obstacles } \\
\text { A15. The ability to accept stimuli }\end{array}$} & 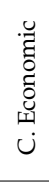 & $\begin{array}{l}\text { C1. Autonomous economic support system (Chiang \& Chang, } 2014 \text { [38]) } \\
\text { C2. Community capital (Creation of Job Opportunity) } \\
\text { (Choi \& Sirakaya, 2006 [37]) } \\
\text { C3. Economic income (distribution of resources/power) } \\
\text { (Choi \& Sirakaya, 2006 [37]; Ciftcioglu, 2017 [14]; Wu \& Huang, } 2011 \text { [40]) } \\
\text { C4. Over-reliance on external economic support (Khalili et al., 2015 [42]) }\end{array}$ \\
\hline & & 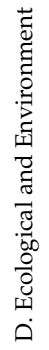 & $\begin{array}{l}\text { D1. Natural disaster recovery capacity (Chiang \& Chang, } 2014 \text { [38]) } \\
\text { D2. Ecological resources and space maintenance capacity } \\
\text { (Chiang \& Chang, 2014 [38]) } \\
\text { D3. Growth management capability (Chiang \& Chang, 2014 [38]) } \\
\text { D4. Conservation and maintenance of biological diversity } \\
\text { (Ciftcioglu, 2017 [14]) } \\
\text { D5. Protection and maintenance of agricultural production } \\
\text { (Ciftcioglu, 2017 [14]) }\end{array}$ \\
\hline 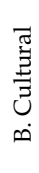 & $\begin{array}{l}\text { B1. The preservation of cultural resources (Chiang \& Chang, } 2014 \text { [38]) } \\
\text { B2. Society cultural fabric (Choi \& Sirakaya, 2006 [37]) } \\
\text { B3. Local culture and history inheritance capability } \\
\text { (Chiang \& Chang, 2014 [38]) } \\
\text { B4. Maintain the traditional ancestral teachings and respect for } \\
\text { ancestral norms }\end{array}$ & 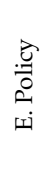 & $\begin{array}{l}\text { E1. Talent cultivation ability (Chiang \& Chang, } 2014 \text { [38]) } \\
\text { E2. Local political participation (election) (Choi \& Sirakaya, } 2006 \text { [37]) } \\
\text { E3. Community leadership (Leadership and resource allocation } \\
\text { capabilities) (Khalili et al., 2015 [42]) }\end{array}$ \\
\hline
\end{tabular}

Source: All indicators were derived from the past literature and in-depth interview of this study.

\subsection{Procedures of the Fuzzy Delphi Method (FDM)}

Fuzzy Delphi Method (FDM) was used to develop evaluation criteria and performance indicators. The traditional Delphi technique process is laborious and time-consuming; it often ignores or distorts expert opinion and other factors. In 1970, Bellman and Zadeh firstly proposed the Fuzzy Theory in decision-making. Now, the Fuzzy Theory has been widely used in various research fields. The Fuzzy Delphi Method (FDM), as its name suggests, is the integration of Fuzzy Theory with the traditional Delphi Method in order to resolve the shortcomings of the traditional Delphi method [47]. Therefore, this study used the Fuzzy Delphi Method to reduce the number of surveys and thoroughly take into account experts' opinions and allow for the inevitable ambiguity of the interview process.

The five steps of FDM are detailed as follows by using Chang, Yu, \& Yang's [48] suggestions:

Step 1: When all the evaluation indicators were confirmed, the expert committee was organized immediately to evaluate each indicator's content. Focusing on the level of importance of the assessment, the value range was specified. The minimum value of this value range indicates the "most conservative cognitive value" by the expert when it comes to the quantified score of the assessed item. On the other hand, the maximum value of the value range represents the "most optimistic cognitive value" as far as the quantified score of the assessed item is concerned.

Step 2: The most conservative and optimistic values were calculated. The extraordinary values outside of the two standard deviations were then deleted, and the fuzzy theory was applied to calculate the minimum value $\mathrm{C}_{L}^{i}$, geometric mean $\mathrm{C}^{i}{ }_{M}$, and maximum value $\mathrm{C}^{i}{ }_{u}$ in the conservative value, as well as the minimum value $\mathrm{O}_{L}^{i}$ geometric mean $\mathrm{O}_{M}^{i}$, and maximum value $\mathrm{O}_{U}^{i}$ in the optimistic value.

Step 3: The conservative value of the triangular fuzzy number for every assessment item i; $\mathrm{C}^{i}=\left(\mathrm{C}_{L}^{i}{ }_{2} \mathrm{C}^{i}{ }_{M}, \mathrm{C}^{i} u\right)$ and the triangular fuzzy number of the "most optimistic cognitive value" were calculated, $\mathrm{O}^{i}=\left(\mathrm{O}_{L}^{i}, \mathrm{O}_{M}^{i}, \mathrm{O}^{i} U\right)$ as shown in Figure 3.

Step 4: Next, the experts' consensus level $\mathrm{G}^{i}$ were calculated in three ways:

(1) If the triangular fuzzy numbers demonstrate no overlapping, as $\mathrm{C}_{U}^{i} \leq \mathrm{O}_{L}^{i}$, it implies that the sentiment intervals of experts show a consensus. If that is the case, the evaluation item $\mathrm{i}$ "value importance level that has reached 
an agreement" $\mathrm{G}^{i}$, equals the average of $\mathrm{C}^{i}{ }_{M}$ and $\mathrm{O}^{i}{ }_{M}$. The calculation Equation (1) was shown as below:

$$
\mathrm{G}_{i}=\frac{\mathrm{C}_{M}^{i}+\mathrm{O}_{M}^{i}}{2}
$$

If two triangular fuzzy numbers overlap, then $\left(\mathrm{C}^{i}{ }_{U}>\mathrm{O}_{L}^{i}\right)$ and $\mathrm{Z}^{i}>\mathrm{M}^{i}$, where $\mathrm{Z}^{i}=\mathrm{C}^{i} U-\mathrm{O}_{L}^{i}$ and $\mathrm{M}^{i}=\mathrm{O}^{i}{ }_{M}-\mathrm{C}^{i}{ }_{M}$. Furthermore, the gray area of the fuzzy relationship is smaller than the interval between the experts' evaluation items "optimist cognitive of the geometric mean" and "conservative cognitive of the geometric mean." Although the sentiment intervals of the experts have no consensus sections, the sentiment of the experts that gave extraordinary values and the sentiments of the other experts did not demonstrate significant disparities, leading to sentiment divergence. In that case, the "value importance that has reached a consensus" of assessment item $i$ is calculated based on the following Equation.

$$
\mathrm{F}^{i}\left(x_{j}\right)=\left\{\int_{x}\left\{\min \left[\mathrm{C}^{i}\left(x_{j}\right), \mathrm{O}^{i}\left(x_{j}\right)\right]\right\} d_{x}\right\}
$$

(3) If two triangular fuzzy numbers demonstrate overlapping, then $\left(\mathrm{C}^{i} u>\mathrm{O}_{L}^{i}\right)$ and $\mathrm{Z}^{i}<\mathrm{M}^{i}$, it implies that the gray area with a fuzzy relationship $\mathrm{Z}^{i}$ is smaller than the interval range of evaluation items "optimistic cognition of the geometric mean" and "conservative cognition of the geometric mean" $\left(\mathrm{M}^{i}\right)$. It implies that the sentiment interval values of the experts had no agreement and that the sentiment of the experts that gave extraordinary values and the sentiments of the other experts showed significant disparities, leading to a divergence of opinion.

Step 5: Finally, the important criteria can be selected if the consensus values $\mathrm{G}^{i}$ are greater than a given threshold value between 6.0 and 7.0 (Kuo \& Chen, 2008), the formula of $\mathrm{G}^{i}$ calculation is shown below.

$$
\mathrm{G}^{i}=\left\{x_{j} \mid \max U_{\mathrm{F}^{i}}\left(x_{j}\right)\right\}
$$

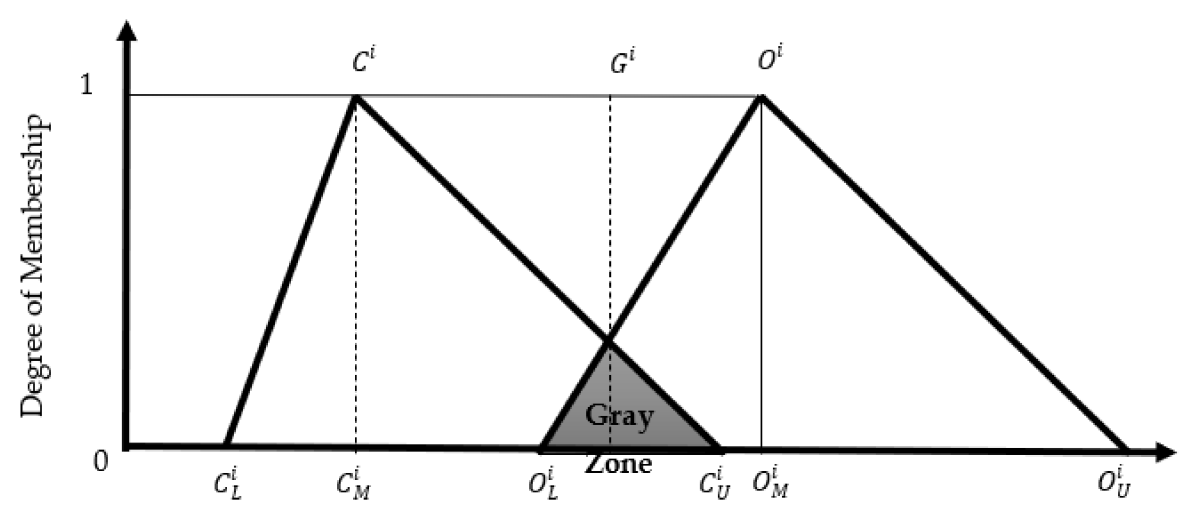

Figure 3. Double triangular fuzzy numbers, cited from Hsu, Kuo, Shyu and Chen [49].

\section{Results}

According to the results of the expert questionnaires and the application of Murray, Pipino, and Gigch's [50] Fuzzy Delphi process, we used Microsoft Excel to obtain the minimum value $\mathrm{Ci}$ (the most conservative value) and the maximum value Oi (the most optimistic value) given by all the experts. The fuzzy theory was then adopted to calculate the minimum value $C^{i}$, geometric mean $C^{i}{ }_{M}$, and maximum value $C^{i}{ }_{U}$ in the conservative value, as well as the minimum value $\mathrm{O}_{L}^{i}$, geometric mean $\mathrm{O}_{M}^{i}$, and maximum value $\mathrm{O}_{U}^{i}$ 
in the optimistic value. Next, the conservative and optimistic values of the triangular fuzzy number were obtained. Lastly, the consensus level $G^{i}$ was calculated. $G^{i}$ refers to the "value importance level that has reached a consensus" as far as the opinions of the experts are concerned.

In terms of the filtering indicator, the decision-maker set the threshold value $S$; this study was done based on the threshold value being the majority result from previous studies, and the requirement for this study was set as $6 . \mathrm{G}^{i}$ values below six can be deleted $[47,48]$. Eliminated items are shaded, and the final results of the FDM are shown in Tables 3-7.

Table 3. Consensus values ( $\mathrm{G}^{i}$ values) calculated using fuzzy Delphi method-Social Aspects.

\section{Social Aspects of the Indicators Items}

\begin{tabular}{|c|c|c|c|c|}
\hline Indicator Items & $\mathrm{Z}^{i}$ & $\mathbf{M}^{i}$ & $\mathbf{M}^{i}-\mathbf{Z}^{i}$ & $\mathrm{G}^{i}$ \\
\hline A1.1 Mutual care amongst organizations and groups & 1 & 4.71 & 3.71 & 6.47 \\
\hline A1.2 Social space for continuation of traditional culture & 2 & 4.46 & 2.46 & 6.15 \\
\hline A2.1 Integration of internal mechanisms of various organizations and groups & 0 & 4.18 & 4.18 & 6.00 \\
\hline A2.2 Organizational ability for continuation of traditional culture & 3 & 3.79 & 0.79 & 6.61 \\
\hline A3.1 Tribes people's affirmation of the tribe and personal work abilities & 1 & 4.34 & 3.34 & 6.47 \\
\hline A3.2 The ability to restore the traditional tribal lifestyle & 1 & 4.15 & 3.15 & 6.39 \\
\hline A4.1 The extent to which tribes people participate in diverse activities & 2 & 3.80 & 1.80 & 6.71 \\
\hline $\begin{array}{l}\text { A4.2 The extent to which tribes people participate in tribal affairs related to } \\
\text { society development }\end{array}$ & 3 & 3.34 & 0.34 & 7.19 \\
\hline A5.1 The extent to which tribes people support the Indigenous community development & 1 & 3.81 & 2.81 & 6.66 \\
\hline A5.2 Feedback mechanism to the tribe or the tribe's people & 3 & 3.43 & 0.43 & 5.78 \\
\hline A6.1 Autonomous mutual aid mechanism during tribal emergency situation/disaster & 1 & 3.51 & 2.51 & 7.46 \\
\hline A6.2 Mitigation mechanism for when the tribes face a division of opinions. & 1 & 3.65 & 2.65 & 6.57 \\
\hline A7.1 Whether there is sufficient educational resources and facilities within the tribe. & 1 & 4.00 & 3.00 & 6.44 \\
\hline A7.2 Whether there is a program to teach traditional culture lessons & 2 & 4.20 & 2.20 & 6.06 \\
\hline A8.1 The degree of understanding of "Gaya" by the tribe's people & 1 & 3.52 & 2.52 & 7.48 \\
\hline A8.2 The degree of understanding of traditional culture by the tribe's people & 1 & 3.65 & 2.65 & 6.67 \\
\hline A8.3 The degree of the tribe's people mastery of the tribal language & 1 & 3.79 & 2.79 & 6.50 \\
\hline A8.4 The tribe's people have a strong sense of self-recognition for the Seediq & 1 & 3.52 & 2.52 & 7.51 \\
\hline A9.1 Tribal leaders have the ability to create and innovate & 0 & 4.12 & 4.12 & 7.00 \\
\hline A9.2 Capabilities of vision construction and consolidation & 0 & 4.19 & 4.19 & 7.00 \\
\hline A10.1 Whether the tribe has an open and transparent information platform & 1 & 3.82 & 2.82 & 6.47 \\
\hline $\begin{array}{l}\text { A10.2 Whether the tribe's people understand and trust the use of internal and external } \\
\text { resources or subsidies }\end{array}$ & 2 & 3.82 & 1.82 & 6.76 \\
\hline A11.1 Whether the tribe provides the opportunity for young generation to learn and be hired & 1 & 4.03 & 3.03 & 7.42 \\
\hline A11.2 Whether the tribe has like-minded young people working together for the vision & 1 & 3.63 & 2.63 & 7.39 \\
\hline $\begin{array}{l}\text { A12.1 Whether the tribe has the support of external experts or consultants in the process of } \\
\text { Indigenous community development }\end{array}$ & 0 & 4.07 & 4.07 & 7.00 \\
\hline $\begin{array}{l}\text { A12.2 Whether the tribe has the support of other external groups, organizations in the } \\
\text { process of Indigenous community development }\end{array}$ & 0 & 3.93 & 3.93 & 7.00 \\
\hline A13.1 Feeling of optimism and contentment with the present condition & 4 & 3.07 & -0.93 & 3.78 \\
\hline A13.2 Natural characteristics of being down-to-earth and hard-working & 7 & 3.29 & -3.71 & 4.82 \\
\hline
\end{tabular}


Table 3. Cont.

\begin{tabular}{|c|c|c|c|c|}
\hline \multicolumn{5}{|l|}{ Social Aspects of the Indicators Items } \\
\hline Indicator Items & $\mathrm{Z}^{i}$ & $\mathbf{M}^{i}$ & $\mathbf{M}^{i}-\mathbf{Z}^{i}$ & $\mathrm{G}^{i}$ \\
\hline A13.3 Sense of humor of the Indigenous people & 6 & 3.08 & -2.92 & 4.50 \\
\hline $\begin{array}{l}\text { A14.1 Whether the tribe has groups and organizations that can promote Indigenous } \\
\text { community development and resolve tribal disputes }\end{array}$ & 2 & 3.93 & 1.93 & 6.92 \\
\hline A14.2 The ability of the tribe to reconcile different subgroups & 2 & 4.10 & 2.10 & 6.89 \\
\hline A15.1 Whether the tribe has an open mind for acceptance of external stimuli & 1 & 3.89 & 2.89 & 6.49 \\
\hline $\begin{array}{l}\text { A15.2 Whether the tribe can accept external stimuli, enabling the tribe to turn around } \\
\text { and grow }\end{array}$ & 1 & 3.86 & 2.86 & 6.50 \\
\hline
\end{tabular}

Table 4. Consensus values ( $G^{i}$ values) calculated using fuzzy Delphi method-Cultural Aspect.

\begin{tabular}{|c|c|c|c|c|}
\hline \multicolumn{5}{|l|}{ Indicator Items for Cultural Aspects } \\
\hline Indicator Items & $\mathrm{Z}^{i}$ & $\mathbf{M}^{i}$ & $\mathbf{M}^{i}-\mathbf{Z}^{i}$ & $\mathrm{G}^{i}$ \\
\hline B1.1 Maintain and restore the traditional image of the tribe & 1 & 4.03 & 3.03 & 6.55 \\
\hline B1.2 The mechanism for inheriting traditional wisdom & 1 & 4.03 & 3.03 & 7.41 \\
\hline B2.1 The tribe's insistence on preserving the integrity of the traditional culture & 1 & 3.84 & 2.84 & 7.35 \\
\hline $\begin{array}{l}\text { B3.1 The mechanism of the tribe for maintaining traditional worship ceremonies, hunting, } \\
\text { weaving, mother tongue, and other cultures }\end{array}$ & 2 & 3.99 & 1.99 & 7.03 \\
\hline $\begin{array}{l}\text { B3.2 Whether internally there is an ability to investigate and record the collection and } \\
\text { construction of local traditional cultural history }\end{array}$ & 2 & 4.03 & 2.03 & 6.82 \\
\hline $\begin{array}{l}\text { B4.1 Whether the tribe's people can maintain traditional ancestral teachings and respect } \\
\text { ancestral norms }\end{array}$ & 1 & 3.33 & 2.33 & 6.56 \\
\hline
\end{tabular}

Table 5. Consensus values ( $\mathrm{G}^{i}$ values) calculated using fuzzy Delphi method-Economic Aspect.

\section{Indicator Items for Economic Aspect}

\section{Indicator Items}

C1.1 Whether the tribe has an independent economic support system, such as: Credit Union, etc.

C2.1 Whether the tribe has a self-sufficient industry

C2.2 Whether the tribe's people have the possibility of employment

C3.1 Stability of economic income of people in the tribe

C4.1 When facing an emergency situation/disaster, the tribe's excessive dependence on subsidies and external resources

\begin{tabular}{cccc}
$\mathrm{Z}^{i}$ & $\mathbf{M}^{i}$ & $\mathbf{M}^{i}-\mathbf{Z}^{i}$ & $\mathrm{G}^{i}$ \\
1 & 3.83 & 2.83 & 6.58 \\
0 & 3.74 & 3.74 & 7.00 \\
\hline 2 & 3.68 & 1.68 & 8.53 \\
\hline 2 & 4.03 & 2.03 & 6.22 \\
\hline 2 & 3.80 & 1.80 & 5.86 \\
\hline
\end{tabular}

Table 6. Consensus values ( $\mathrm{G}^{i}$ values) calculated using fuzzy Delphi method-Environmental Aspect.

\begin{tabular}{|c|c|c|c|c|}
\hline \multicolumn{5}{|c|}{ Indicator Items for Environmental Aspects } \\
\hline Indicator Items & $\mathrm{Z}^{i}$ & $\mathbf{M}^{i}$ & $\mathbf{M}^{i}-\mathbf{Z}^{i}$ & $\mathrm{G}^{i}$ \\
\hline D1.1 The fostering of tribal awareness regarding disaster relief & 1 & 3.84 & 2.84 & 5.66 \\
\hline D1.2 The capability of the tribe regarding an overall disaster relief plan & 1 & 3.72 & 2.72 & 5.68 \\
\hline $\begin{array}{l}\text { D1.3 Resilience ability for construction and facilities' recovery during emergency } \\
\text { situations/disasters }\end{array}$ & 0 & 4.15 & 4.15 & 6.00 \\
\hline $\begin{array}{l}\text { D2.1 The tribe's people possess ecological resources and ability to create space } \\
\text { for themselves }\end{array}$ & 2 & 4.51 & 2.51 & 6.82 \\
\hline
\end{tabular}


Table 6. Cont.

\begin{tabular}{|c|c|c|c|c|}
\hline \multicolumn{5}{|c|}{ Indicator Items for Environmental Aspects } \\
\hline Indicator Items & $\mathrm{Z}^{i}$ & $\mathbf{M}^{i}$ & $\mathbf{M}^{i}-\mathbf{Z}^{i}$ & $\mathrm{G}^{i}$ \\
\hline $\begin{array}{l}\text { D3.1 The mechanism to avoid the tribal land resources being used for } \\
\text { improper development }\end{array}$ & 5 & 4.06 & -0.94 & 5.76 \\
\hline $\begin{array}{l}\text { D4.1 Whether the tribe has a mechanism for the conservation and maintenance of } \\
\text { biological diversity }\end{array}$ & 2 & 3.65 & 1.65 & 6.21 \\
\hline D5.1 Whether the tribe has the ability to introspect conventional farming & 2 & 4.32 & 2.32 & 6.84 \\
\hline D5.2 The ability to preserve traditional ethnic plantation and crops & 1 & 3.68 & 2.68 & 7.41 \\
\hline
\end{tabular}

Table 7. Consensus values ( $\mathrm{G}^{i}$ values) calculated using fuzzy Delphi method-Policy-related Aspect.

\begin{tabular}{|c|c|c|c|c|}
\hline \multicolumn{5}{|l|}{ Indicator Items for Environmental Aspect } \\
\hline Indicator Items & $\mathrm{Z}^{i}$ & $\mathbf{M}^{i}$ & $\mathbf{M}^{i}-\mathbf{Z}^{i}$ & $\mathrm{G}^{i}$ \\
\hline E1.1 The mechanism for tribal talent training & 3 & 3.63 & 0.63 & 6.61 \\
\hline E2.1 The extent to which tribes people participate in local politics & 6 & 2.98 & -3.02 & 5.03 \\
\hline $\begin{array}{l}\text { E2.2 The extent of participation of local politics in affecting Indigenous } \\
\text { community development }\end{array}$ & 6 & 2.97 & -3.03 & 5.07 \\
\hline $\begin{array}{l}\text { E3.1 Whether the tribal leaders have the ability to integrate the various subgroups and } \\
\text { organize groups }\end{array}$ & 2 & 3.52 & 1.52 & 6.15 \\
\hline
\end{tabular}

A total of 5 domains, 31 assessment types, and 56 assessment items were drawn out in the preliminary stage. By screening the FDM expert consensus, a total of 5 assessment types and 11 evaluation indicators were deleted. The Indigenous resilience index was divided into three levels based on the screening results. The first layer contains five domains (i.e., social, cultural, economic, environmental, and policies); the second layer has 26 assessment types; the third layer has 45 evaluation indicators (please see Figure 4 for more details of each evaluation indicator), accounting for $80.35 \%$ of the total number of screenings before the assessment. This study is based on the type of evaluation in the second layer as follows:

(1) Social resilience includes 14 types: "Mutual support and care", "Diversified community participation", "Community effectiveness", "Social, community involvement", "Social support", "Social cohesion", "Educational resources and accessibility", "Sense of belonging to the tribe", "Creativity and innovation ability", "Communication and information", "Mechanisms to encourage young people to return home", "External links", "Ability to reduce obstacles", and "Ability to accept stimuli".

(2) Cultural resilience includes four types: "the preservation of cultural resources," "social and cultural fabric," "Culture and heritage inheritance ability", and "maintenance of traditional ancestral training and respect for ancestral norms."

(3) Economic resilience includes three types: "autonomous economic support system," "community capital (creation of job opportunity)," and economic income (allocation of resources/power)."

(4) Ecological and environmental resilience includes three types: "ecological resources and space maintenance capacity," "conservation and maintenance of biodiversity", and "protection and maintenance of agricultural production."

(5) Policy-related resilience includes two types: "talent cultivation ability" and "community leadership (leadership and resource allocation capabilities)." 


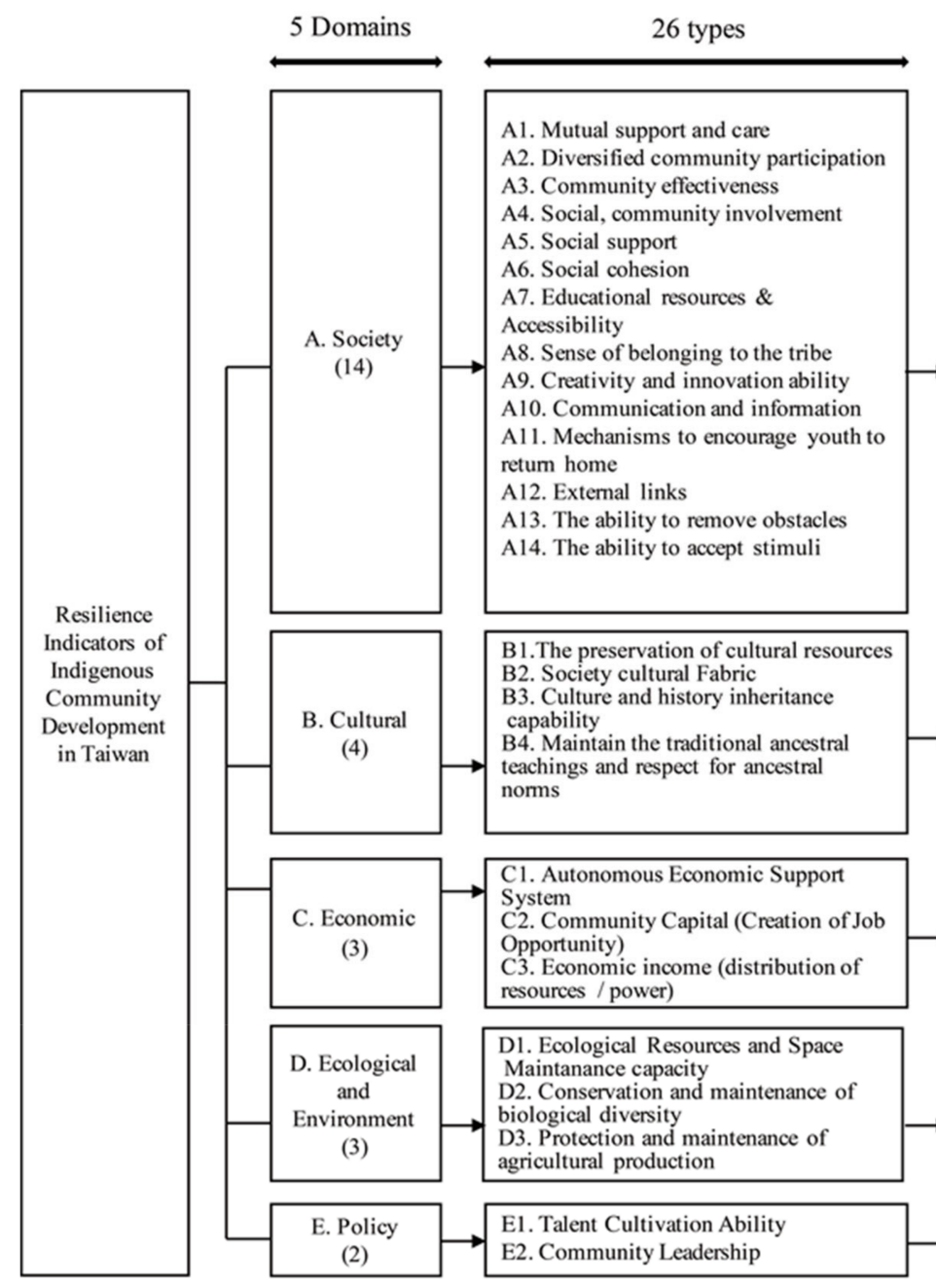

45 evaluation indicators

A1.1 Mutual care amongst organizations and groups A1.2 Social space for continuation of traditional culture

fontinuation of traditional culture

A3.1 Tribes people's affirmation of the tribe and personal work abilitics A3.2 The ability to restore the traditional tribal life style

A4.1 The extent to which tribes people participate in diverse activities A4.2 The extent to which tribes people participate in tribal affairs related to society development

A6.1 Autonomous muttual aid mechanism during tribal emergency situation / disaster A6.2 Mitigation mechanism for when the tribes face a division of
(n) opinions A7.1 Whether there is sufficient cducational resources and facilities within the tribe A7.2 Whether there is a program to teach traditional culture lessons
A8.1 The degree of understanding of "Gaya" by the tribes people A8.2 The degree of understanding of traditional culture by the tribes people A8.3 The A 8 gree of the tribes people mastery of the tribal language $\$ 8.4$ The tribes people have a strong sense of self-recognition for the Seediq

A9.1 Tribal leaders have the ability to create and innovate A9.2 Capabilities of vision construction and consolidation

A10.1 Whether the tribe has an open and transparent information platform A10.2 Whether the tribes people understand and trust the use of internal and

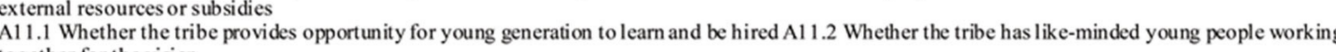
together for the vision

the support of external experts or consultants in the process of tribal development A12.2 Whether the tribe has support of other A13.1 Whether the tribe has groups and organizations that can promote tribal development and resolve tribal disputes A13.2 The ability of the tribe to reconcile different factions
A14.1 Whether the tribe has an open mind for acceptance of external stimuli A14.2 Whether the tribe can accept external stimuli, enabling the tribe to tum

\section{B1.1 Maintain and restore the traditional image of the tribe B1.2 The mechanism for inheriting traditional wisdom}

B2.1 The tribe's insistence on preserving the integrity of the traditional culture

B3.1 The mechanism of the tribe for maintaining traditional worship ceremonies, hunting, weaving, mother tongue and other cultures B3.2 Whether

internally there is an ability to investigate and record the collection and construction of local traditional cultural history

B4.1 Whether the tribes people can maintain traditional ancestral teachings and respect ancestral norms

C1.1 Whether the tribe has an independent economic support system, such as: Credit Union... and so on

C2.1 Whether hic rribe has a self-sufficient industry C2.2 Whether the tribes people have the possibility of employmen

C3.1 Stability of economic income of people in the tribe

D1.1 The tribes people possess ecological resources and ability to create space for themselve

D3.1 Whether the tribe has the ability to introspect the conventional farming D3.2 The ability to preserve traditional ethnic plantation and crops

El.1 The mechanism for tribal talent training
E2.1 Whether the tribal leaders have the ability to integrate the various factions and organize groups

Figure 4. Key Resilience Indicators for Indigenous Community. 


\section{Discussion}

The following are five aspects based on the discussion of the Alang Tongan's resilience in social (A-14 types of resilience evaluation), cultural (B-4 types of resilience evaluation), economic (C-3 types of resilience evaluation), ecological and environmental (D- 3 types of resilience evaluation), and policies (E- 2 types of resilience evaluation) to carry out further discussions.

\subsection{Multi-Structure of Indigenous Social Resilience}

In the evaluation type of communications and information (A10), the Alang Tongan Monthly is a practical example. Both the NCNU team and the residents co-created the social media. On 25 October 2015, the first issue of the local newspaper was released, enabling the tribe to have an open platform for information, enabling the elders and young people to regain their cultural identity, further convey traditional wisdom, and arouse everyone's public awareness. The second issue of Alang Tongan Monthly also immediately received the attention of the Indigenous Television Channel, whose news team conducted interviews with the residents. In addition, the Alang Tongan Monthly was also published through Blogs and Facebook, thus enabling the tribe and the community to have more internal and external interaction. Furthermore, the tribe's newspaper improves the tribe's social participation and also increases tribal exposure and visibility.

In the evaluation type of mutual care ability (A1), the NCNU elderly care team has been established for years. There are also summer camp activities organized for the local school children, helping to enhance the children's academic performance and cultivating healthy bodies and minds.

There are also countless disputes and conflicts in the tribes caused by long-term economic problems such as the outflow of young people, the loss of culture, and land ownership, thus creating poor cohesion of the internal groups in many Indigenous communities [51]. However, the tribe has always shown a high degree of unity in several key periods. For example, the tribe has brought together the elderly and the young people to work on traditional house reconstruction (A13). When the landslide occurred in June 2019, caused by the heavy monsoon rains, the residents teamed up to resolve the relevant issues (A6); at the same time, they developed the initiative and autonomous team spirit amongst the tribe members, as well as fully showing the cohesion of the Alang Tongan.

The Alang Tongan has a number of sub-organizations, such as: "Nanfeng Community Development Association", "Industrial Promotion and Development Association", "Production and Marketing Group" and so on, allowing tribal people to be more involved and enthusiastic with regards to public affairs and activities (A2). This shows that the tribes have a solid foundation in terms of consensus formation and interactive, cooperative experience.

When the tribal youth return home, they help with the development of the tribe based on the inflow of external resources (A11). The external stimuli and innovation allow the tribe to have the opportunity to flip and grow. The level of the connection to external resources affects tribal resilience. However, for other Indigenous tribes, when the input of external resources has not met the needs due to competition for resources, it may result in the original system disintegrating or creating other drawbacks [52].

\subsection{Gaya-Centered Indigenous Cultural Resilience}

The Seediq people adhere to the Gaya guidelines for all codes of conduct, and these are the intangible cultural connotations of the Seediq. Gaya is also the basis of customary laws and standards between the ethnic groups and the norms that symbolize the life of the entire Seediq family. Therefore, in the Indigenous cultural resilience indicators, with the awakening of the ancestral spirit in the interaction between the people and the land, the humans are not the owners of the earth, the people just live on it. People's good or bad fortune depends on the fitting together of the people and the ancestral spirit; it is not just decided by humans (B4). This reverence for the supernatural forces, the reconstruction of Indigenous traditional culture and ancestral beliefs indirectly established respect for the 
environment and caring for the earth. Through the traditional process of learning, such as weaving, rattan, etc., combined with their real life, the establishment of mother-tongue teaching and Indigenous customs residents are able to affirm their roots, and thus the identity of the tribe and improve the participation in tribal affairs (B1 and B3).

\subsection{Indigenous Economic Resilience in the Innovative Economic Model}

Earlier in the Alang Tongan, there was no post office or bank; in 1965, the first Indigenous Credit Union (CU) was established, mainly to assist the poor and serve their members rather than maximize profits (C1). In recent years, the insurance business has been provided as a necessary service for people's livelihood. Spaces of the CU has also been used for the day-care center for the tribal elderly, children's after-school care, and tribal mothers' classroom as a way to provide welfare services to the community. In addition, the end-of-year surplus of the CU has also contributed by giving back to its members, organizing food and agriculture education tours, all with the purpose of helping the residents to move forward [40]. As a result, the CU continues to be one of the important economic resilience supports to this Indigenous community.

In 2017, the project "Table in the Paddy" was introduced to the community by The Soil and Water Conservation Bureau (SWCB). The "Table in the Paddy" project is a new business model in rural tourism and rethinks the connection between land and food, rural village and residents. It tries to create higher value for the rural area and draw people closer to the land (C3).

In addition, the Council of Indigenous Peoples of the central government also provided entrepreneurship counseling and management courses, allowing people to start a new business and then return home to create more employment opportunities, giving the tribal people another career choice (C2). Recently, the Alang Tongan has also introduced the concept of a cooking school from Thailand with the building of the Plale Cooking School (Plale means butterfly in Seediq). From the original farm to the table, through Seediq learning and experiences - in-depth understanding of Indigenous food and culture-it has also created tribal youth employment opportunities. In recent years, the cooking school, farm-to-table tours, coffee and tea-making courses, hunter school, and shooting ranch provide a stable income and increased local economic growth.

\subsection{Constructing a Sustainable Homeland by Applying Ecological and Environmental Resilience}

Starting from 2012, through the environment and butterfly rehabilitation, the Alang Tongan people built up a butterfly conservation project, protected the butterflies' habitat, and developed ecotourism (D2). The purpose of the conservation programs is to cultivate the butterfly habitat, and more than 200 species of butterflies were recovered in this small area (about 370 species of butterfly have been recorded in Taiwan).

The Alang Tongan also constructed a handmade trail based on the Seediq's ancient footpaths with the assistance of the Thousand Mile Trail Club and NCNU professors and students in 2015. In 2017, tribal people began to construct and rehabilitate seven ecological ponds and restore the ecosystem, allowing the original habitat in the Meixi Creek to be available again to many creatures, restoring its vitality and getting a balance of conservation rehabilitation and economic development (D1).

However, in June 2019, the monsoon rain led to the main road being blocked because of a landslide. Through the assistance of the SWCB and the local government, this was immediately resolved and traffic was able to get through in a day. This reveals the ability of the Along Tongan for rapid, short-term recovery. The NCNU has also helped the Alang Tongan to locate all hazardous locations by using an Unmanned Aerial Vehicle (UAV) and Google Earth. This will also benefit disaster prevention and education in the future.

\subsection{Policy-Related Resilience Strengthen the Internal Cohesion}

With regard to the Alang Tongan Monthly circulation and distribution, it also focused on the local cultivation and established the tribal youth's long-term participation in the 
editorial team. Recently, non-toxic, natural, and non-human growth hormone farming are also considered friendly to the land and form part of the ecological resilience. In order to increase the tribe's economic growth, it is necessary to cultivate relevant personnel involved in the process (E1).

The Indigenous community development process includes short-term and long-term resilience capabilities. Short-term resilience is particularly evident in society and the environment. For example, in the context of natural disasters, the autonomy of the tribe, and the restoration of the environment, the Alang Tongan is considered to have a faster recovery capacity. However, the Seediq culture and heritage preservation need long-term cultivation in the cultural context. This shows that the Indigenous community development is usually based on short-term resilience. We should pay more attention to long-term resilience and recovery capability in the future.

\section{Conclusions}

Choi and Sirakaya [37] proposed a set of six types of community tourism indicators, including politics (32), society (28), ecology (25), economics (24), technology (3), and culture (13), a total of 125 indicators. Their study pointed out that community tourism management mainly involves residents, stakeholders, and the government. It is believed that management should be focused on the community and should have direct involvement with the residents in the planning. This will also indirectly affect the decision-making and fair distribution of benefits and encourage the establishment of local advisory committee organizations for public participation in planning and decision-making to provide an effective communications platform.

Our study is in line with the findings of Choi and Sirakaya [37], both focusing on the applications of social-related indicators, which showed that community sustainable development indicators are a social-oriented early warning mechanism that emphasizes conservation and minimizes negative impacts.

The Indigenous community development-related work to the tribe is mainly volunteered and done autonomously. For example, the researchers of Taiwan Endemic Species Research Institute (TESRI) enter into the Alang Tongan for butterfly research and, through long-term companions, have designed a curriculum in the community that has encouraged ecological conservation awareness. Culturally, it is also serves as a cultural revitalization movement by reconstructing traditional houses, collecting Indigenous ancient music, and weaving. In addition, in recent years, young people who returned home carried out creative ideas from running a new business model, such as providing Indigenous cultural tours, introducing a Seediq-style cooking school and the use of AI devices in the self-guiding system. This will increase tribal economic growth and benefit Indigenous community development. It is also the concept of change and innovation mentioned in the definition of resilience.

There have been many factors that have benefited and hindered the development of tribes, according to Lew [4], who comprehensively discussed the "adaptive cycle". In the current stage of development, the Alang Tongan should be at the stage of the "exploitation and growth $(\mathrm{r})^{\prime \prime}$. The tribe has experienced impacts from many of the internal and external aspects of the natural disasters (such as the 921 earthquakes, 72 floods, etc.), cultural loss (traditional culture, ethnic language loss), and social structural change (youth population outflow). On the other hand, the tribes have also continued to promote the regional revitalization, re-activation of tribes, and other works, including the reconstruction of traditional houses, butterfly habitat rehabilitation, the construction of ecological ponds, and promotion of tribal-related industries. Based on Lew's [4] observation, the Alang Tongan does not have to go through all four stages of the cycle. As long as the tribe has the capacity to innovate and adapt to the changing environments, the Alang Tongan may avoid the recession or even the collapse phases. 


\section{Research Limits and Future Research Recommendations}

In acknowledging the limitations of the current research, we suggest that follow-up researchers may extend these resilience indicators to other Indigenous tribes. Taiwan's Indigenous peoples are divided into 16 tribes. This study is mainly based on one specific Indigenous tribe in Taiwan. These indicators may not be generalized globally because of the different cultural backgrounds and ethnic disparity. In addition, a focus on Indigenous rights, autonomy, and sovereignty in the context of the particular constraints of current legal, policy, and political settings in Taiwan may be included in future research. The 26 types of assessment will also be the factors that must be taken into account in the process of adaptation and reconstruction when the community is faced with emergencies/catastrophes. Methodology-wise, Graham and Dadd [53] urged for further and continued analytical attention on Indigenous tourism encounters in deeply colonised- yet Indigenous- place in order to understand the social and cultural impacts. Future research may draw on the words of the Indigenous tour operators to document the kinds of 'deep-colonising' [54] narratives and assumptions the operators encounter during their tours and within the tourism industry.

Although the FDM has been used extensively in humanities, management, business, physical science, and engineering, it is subject to important limitations. Saffie, Shukor, and Rasmani [55] indicated that almost all prior research utilized the triangular fuzzy number to characterize linguistic terms in the questionnaire to obtain opinions from the experts. The most well-known methodology has been to aggregate opinions through experts using the maximum and minimum fuzzy values based on the geometric mean model. These techniques ought to be additionally investigated and enhanced to achieve better inference. The claim that FDM can solve the fuzziness of the expert consensus among the group for decision-making should also be proved analytically or experimentally. In addition, FDM has been regularly combined with other methods, such as fuzzy and non-fuzzy Analytic Hierarchy Process (AHP) and fuzzy TOPSIS. Moreover, FDM combined with IPA (Importance Performance analysis) [56] was used extensively to understand the importance and performance of the indicators. Chu \& Guo [57] further presented the Similarity-Based Importance-Performance Analysis, SBIPA; therefore, it is proposed that future research is encouraged to integrate the FDM with an IPA or SBIPA analysis. The average of the "importance" and "performance" of the resilience index is further plotted on the two-dimensional plane coordinates, increasing the convenience of evaluating the indicators and providing a more accurate assessment of the conclusions.

Author Contributions: Conceptualization, Y.-P.T.; Data curation, Y.-C.H. and Y.-Z.J.; Formal analysis, M.-S.L.; Funding acquisition, Y.-P.T.; Investigation, Y.-C.H. and M.-S.L.; Methodology, Y.-P.T.; Project administration, M.-S.L.; Resources, Y.-P.T.; Software, Y.-Z.J.; Supervision, Y.-P.T.; Visualization, M.-S.L.; Writing—original draft, Y.-P.T. and M.-S.L.; Writing—review \& editing, Y.-C.H. and Y.-Z.J. All authors have read and agreed to the published version of the manuscript.

Funding: This research was funded by the Ministry of Science and Technology, Project No. 108-2420H-260 -003 -HS1; 109-2420-H-260 -004 -HS2, 110-2420-H-260 -004 -HS3.

Institutional Review Board Statement: Not applicable.

Informed Consent Statement: Informed consent was obtained from all interviewees involved in the study.

Data Availability Statement: Not applicable.

Acknowledgments: Authors would like to thank the Research Center of Humanistic Innovation and Social Engagement of National Chi Nan University and the contribution of the anonymous reviewers.

Conflicts of Interest: The author declares no conflict of interest. 


\section{References}

1. Pimm, S.L. The complexity and stability of ecosystems. Nature 1984, 307, 321-326. [CrossRef]

2. Adger, W.N. Social and ecological resilience: Are they related? Prog. Hum. Geogr. 2000, 24, 347-364. [CrossRef]

3. Folke, C. Resilience: The emergence of a perspective for social-ecological systems analyses. Glob. Environ. Chang. 2006, 16, 253-267. [CrossRef]

4. $\quad$ Lew, A.A.; Wu, T.-C.; Ni, C.-C.; Ng, P.T. Community tourism resilience: Some applications of the scale, change and resilience (SCR) model. Tour. Resil. 2017, 23-31.

5. Gunderson, L.H. Ecological resilience-In theory and application. Annu. Rev. Ecol. Syst. 2000, 31, 425-439. [CrossRef]

6. Sheppard, V.A.; Williams, P.W. Factors that strengthen tourism resort resilience. J. Hosp. Tour. Manag. 2016, 28, 20-30. [CrossRef]

7. Lew, A.A.; Ng, P.T.; Ni, C.-C.; Wu, T.-C. Community sustainability and resilience: Similarities, differences and indicators. Tour. Geogr. 2016, 18, 18-27. [CrossRef]

8. Costanza, R. The value of natural and social capital in our current full world and in a sustainable and desirable future. In Sustainability Science; Springer: Berlin/Heidelberg, Germany, 2012; pp. 99-109.

9. Haalboom, B.; Natcher, D.C. The Power and Peril of "Vulnerability": Approaching Community Labels with Caution in Climate Change Research. Arctic 2012, 65, 319-327. [CrossRef]

10. Thompson, I.; Mackey, B.; McNulty, S.; Mosseler, A. Forest Resilience, Biodiversity, and Climate Change; Technical Series no. 43; Secretariat of the Convention on Biological Diversity: Montreal, QC, Canada, 2009; pp. 1-67.

11. Walker, B.; Holling, C.S.; Carpenter, S.R.; Kinzig, A. Resilience, adaptability and transformability in social-ecological systems. Ecol. Soc. 2004, 9, 5. [CrossRef]

12. Mercer, J.; Dominey-Howes, D.; Kelman, I.; Lloyd, K. The potential for combining indigenous and western knowledge in reducing vulnerability to environmental hazards in small island developing states. Environ. Hazards 2007, 7, 245-256. [CrossRef]

13. Davidson, D.J. The applicability of the concept of resilience to social systems: Some sources of optimism and nagging doubts. Soc. Nat. Resour. 2010, 23, 1135-1149. [CrossRef]

14. Ciftcioglu, G.C. Assessment of the resilience of socio-ecological production landscapes and seascapes: A case study from Lefke Region of North Cyprus. Ecol. Indic. 2017, 73, 128-138. [CrossRef]

15. Yang, E.; Kim, J.; Pennington-Gray, L.; Ash, K. Does tourism matter in measuring community resilience? Ann. Tour. Res. 2021, 89, 103222. [CrossRef]

16. Berkes, F.; Tsai, H.-M.; Bayrak, M.M.; Lin, Y.-R. Indigenous Resilience to Disasters in Taiwan and Beyond. Sustainability 2021, $13,2435$. [CrossRef]

17. Liu, M.H. Faded Color Wings: Oral History of Catching Butterflies in Alang Tongan/Baike. J. Taiwan Indig. Stud. Assoc. 2016, 6, 73-96.

18. Kashdan, T.B. New developments in emotion regulation with an emphasis on the positive spectrum of human functioning. $J$. Happiness Stud. 2007, 8, 303-310. [CrossRef]

19. Folke, C.; Carpenter, S.R.; Walker, B.; Scheffer, M.; Chapin, T.; Rockström, J. Resilience Thinking Integrating Resilience, Adaptability and Transformability. Ecol. Soc. 2010, 15, 20. [CrossRef]

20. Law \& Regulations Database of The Republic of China. The Indigenous Peoples Basic Law. 2018. Available online: https:/ /aw.moj. gov.tw/ENG/LawClass/LawAll.aspx?pcode=D0130003 (accessed on 25 December 2021).

21. Norris, F.H.; Stevens, S.P.; Pfefferbaum, B.; Wyche, K.F.; Pfefferbaum, R.L. Community resilience as a metaphor, theory, set of capacities, and strategy for disaster readiness. Am. J. Community Psychol. 2008, 41, 127-150. [CrossRef]

22. Lew, A.A. Scale, change and resilience in community tourism planning. Tour. Geogr. 2014, 16, 14-22. [CrossRef]

23. Paton, D.; Millar, M.; Johnston, D. Community resilience to volcanic hazard consequences. Nat. Hazards 2001, $24,157-169$. [CrossRef]

24. Ganor, M.; Ben-Lavy, Y. Community resilience: Lessons derived from Gilo under fire. J. Jew. Communal Serv. 2003, 79, 105-108.

25. Coles, E.; Buckle, P. Developing community resilience as a foundation for effective disaster recovery. Aust. J. Emerg. Manag. 2004, 19, 6-15.

26. Alkon, A.H. Place, stories, and consequences: Heritage narratives and the control of erosion on Lake County, California, vineyards. Organ. Environ. 2004, 17, 145-169. [CrossRef]

27. Pfefferbaum, B.J.; Reissman, D.B.; Pfefferbaum, R.L.; Klomp, R.W.; Gurwitch, R.H. Building resilience to mass trauma events. In Handbook of Injury and Violence Prevention; Springer: Berlin/Heidelberg, Germany, 2008; pp. 347-358.

28. Magis, K. Community resilience: An indicator of social sustainability. Soc. Nat. Resour. 2010, 23, 401-416. [CrossRef]

29. Tsai, C.-H.; Wu, T.-C.; Wall, G.; Linliu, S.-C. Perceptions of tourism impacts and community resilience to natural disasters. Tour. Geogr. 2016, 18, 152-173. [CrossRef]

30. Musavengane, R.; Kloppers, R. Social capital: An investment towards community resilience in the collaborative natural resources management of community-based tourism schemes. Tour. Manag. Perspect. 2020, 34, 100654. [CrossRef]

31. MacDougall, A.S.; Turkington, R. Are invasive species the drivers or passengers of change in degraded ecosystems? Ecology 2005, 86, 42-55. [CrossRef]

32. Butler, R.W. The concept of a tourist area cycle of evolution: Implications for management of resources. In The Tourism Area Life Cycle; Channel View Publications: Bristol, UK, 2006; Volume 1, pp. 3-12.

33. Holling, C.S. Engineering resilience versus ecological resilience. Eng. Ecol. Constraints 1996, 31, 32. 
34. Holling, C.-S.; Gunderson, L.H. (Eds.) Resilience and adaptive cycles. In Panarchy: Understanding Transformations in Human and Natural Systems; Island Press: New York, NY, USA, 2002.

35. Petrosillo, I.; Zurlini, G.; Grato, E.; Zaccarelli, N. Indicating fragility of socio-ecological tourism-based systems. Ecol. Indic. 2006, 6, 104-113. [CrossRef]

36. Berkes, F. Understanding uncertainty and reducing vulnerability: Lessons from resilience thinking. Nat. Hazards 2007, 41, 283-295. [CrossRef]

37. Choi, H.C.; Turk, E.S. Sustainability indicators for managing community tourism. In Quality-of-Life Community Indicators for Parks, Recreation and Tourism Management; Springer: Berlin/Heidelberg, Germany, 2011; pp. 115-140.

38. Chiang, T.S.; Chang, L.Y. Sustainable Community Indicators System-Building of Governance Capacity. Taiwan Found. Democr. 2014, 11, 37-83.

39. Cajete, G.A. Indigenous Science, Climate Change, and Indigenous Community Building: A Framework of Foundational Perspectives for Indigenous Community Resilience and Revitalization. Sustainability 2020, 12, 9569. [CrossRef]

40. Wu, J.Y.; Huang, Y.S. The Establishment of Vulnerability Evaluation Indexes: The Case Study on Shuili Township, Nantou. City Plan 2011, 38, 195-218. [CrossRef]

41. Parsons, M.; Glavac, S.; Hastings, P.; Marshall, G.; McGregor, J.; McNeill, J.; Morley, P.; Reeve, I.; Stayner, R. Top-down assessment of disaster resilience: A conceptual framework using coping and adaptive capacities. Int. J. Disaster Risk Reduct. 2016, 19, 1-11. [CrossRef]

42. Khalili, S.; Harre, M.; Morley, P. A temporal framework of social resilience indicators of communities to flood, case studies: Wagga wagga and Kempsey, NSW, Australia. Int. J. Disaster Risk Reduct. 2015, 13, 248-254. [CrossRef]

43. Council of Indigenous Peoples. Seediq. Available online: https://www.cip.gov.tw/en/tribe/grid-list/2880927AC24CBF01D063 6733C6861689/info.html?cumid=B54B5C7E1E0F994092EDA9D0B7048931 (accessed on 23 January 2022).

44. Yeh, J.H.-Y.; Lin, S.-C.; Lai, S.-C.; Huang, Y.-H.; Yi-Fong, C.; Lee, Y.-T.; Berkes, F. Taiwanese Indigenous Cultural Heritage and Revitalization: Community Practices and Local Development. Sustainability 2021, 13, 1799. [CrossRef]

45. Lee, S.-H.; Chen, Y.-J. Indigenous Knowledge and Endogenous Actions for Building Tribal Resilience after Typhoon Soudelor in Northern Taiwan. Sustainability 2021, 13, 506. [CrossRef]

46. Rowe, G.; Wright, G. The Delphi technique: Past, present, and future prospects-Introduction to the special issue. Technol. Forecast. Soc. Chang. 2011, 78, 1487-1490. [CrossRef]

47. Mayne, A.J. Fuzzy sets, uncertainty, and information. J. Oper. Res. Soc. 1990, 41, 884-886. [CrossRef]

48. Chang, A.-Y.; Yu, H.-F.; Yang, T.-H. A study of the key factors contributing to the bullwhip effect in the supply chain of the retail industry. J. Ind. Prod. Eng. 2013, 30, 433-442. [CrossRef]

49. Hsu, C.-W.; Kuo, T.-C.; Shyu, G.-S.; Chen, P.-S. Low carbon supplier selection in the hotel industry. Sustainability 2014, 6, 2658-2684 [CrossRef]

50. Murray, T.J.; Pipino, L.L.; Van Gigch, J.P. A pilot study of fuzzy set modification of Delphi. Hum. Syst. Manag. 1985, 5, 76-80. [CrossRef]

51. Ji, H.C. Organizational Supports for Aboriginal Tribes' Relocating-Reconstruction after 921 Chi-Chi Earthquake; Chang Jung Christian University: Tainan, Taiwan, 2008.

52. Yen, A.; Lo, E.; Chen, Y. Incentives crowding out effect and the agricultural development of indigenous community: A case study in Quri Community, Jianshih Township, Hsinchu County, Taiwan. J. Geogr. Sci. 2012, 65, 53-78.

53. Graham, M.; Dadd, U.L. Deep-colonising narratives and emotional labour: Indigenous tourism in a deeply-colonised place. Tour. Stud. 2021, 21, 444-463. [CrossRef]

54. Rose, D.B. Land rights and deep colonising: The erasure of women. Aborig. Law Bull. 1996, 3, 6-13. [CrossRef]

55. Saffie, N.A.M.; Shukor, N.M.; Rasmani, K.A. Fuzzy delphi method: Issues and challenges. In Proceedings of the 2016 International Conference on Logistics, Informatics and Service Sciences (LISS), Sydney, Australia, 24-27 July 2016; pp. 1-7.

56. Horng, J.S.; Lin, L. Training needs assessment in a hotel using 360 degree feedback to develop competency-based training programs. J. Hosp. Tour. Manag. 2013, 20, 61-67. [CrossRef]

57. Chu, C.-H.; Guo, Y.-J. Developing similarity based IPA under intuitionistic fuzzy sets to assess leisure bikeways. Tour. Manag. 2015, 47, 47-57. [CrossRef] 